IJBPAS, May, 2018, 7(5): 938-952

ISSN: $2277-4998$

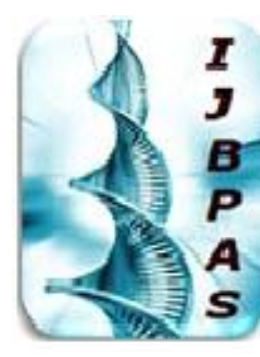

International Journal of Biology, Pharmacy

and Allied Sciences (IJBPAS)

'A Bridge Betusen Caboratory and QRado'

Www.iibpas,com

\title{
PHYTOCHEMICALS AND TERATOGENIC EFFECTS OF WATER EXTRACTS OF RIND OF SELECT FRUITS
}

\author{
ROBERT I. PALAMBERGO, RICH MILTON R. DULAY AND EDEN S. DAVID* \\ Department of Biological Sciences, College of Arts and Sciences, Central Luzon State \\ University, Science City of Munoz, Nueva Ecija, Philippines
}

*Corresponding Author, E-mail: eusdavid@yahoo.com

Received $20^{\text {th }}$ Jan. 2018; Revised $24^{\text {th }}$ Feb. 2018; Accepted $23^{\text {rd }}$ March 2018; Available online $1^{\text {st }}$ May 2018

DOI: https://doi.org/10.31032/IJBPAS/2018/7.5.4452

\begin{abstract}
This paper reported the phytochemicals and teratogenic activities of fruit rind extracts of Annona muricata, Annona squamosa, and Garcinia mangostana. Zebrafish (Danio rerio) embryos at segmentation phase were exposed to various concentrations of the three extracts. Mortality, heartbeat rate, hatchability, delayed growth and malformations of zebrafish were determined. Phytochemical screening revealed that tannins, saponins, flavonoids, terpenoids, and cardiac glycosides were present in A. squamosa, and A. muricata. However, only flavonoid was not detected in G. mangostana. The toxic effects of the extracts were found dependent on the time of exposure, and concentrations of extracts. The most common toxic effect of the three extracts was coagulation. No heartbeat rate was observed to embryos in $1 \%$ and higher concentrations of extracts of A. muricata and G. mangostana and $0.5 \%$ and higher concentrations of A. squamosa extract. The $0.1 \%$ of $A$. muricata extract-treated embryos had $33.33 \%$ hatchability, while no hatched was recorded in those exposed to all concentrations of extracts of A. squamosa and $G$. mangostana. Embryos showed $100 \%$ delayed growth when exposed in $0.5 \%$ of both A. muricata and $A$. squamosa extracts, and in $0.1 \%$ of $G$. mangostana extract. Bent-tail tip embryos were the most common abnormalities and were observed at $0.1 \%$ of both extracts of $A$. muricata and $A$.
\end{abstract}


squamosa. Altogether, rind extracts of the three fruits contain bioactive compounds and exhibit embryo-toxic and teratogenic effects in developing embryos of zebrafish.

\section{Keywords: Annona muricata, Annona squamosa, Garcinia mangostana, zebrafish, phytochemicals}

\section{INTRODUCTION}

Plant-based medicine as valuable remedy for several diseases has been used over the past years. Plants contain various phytochemicals such as alkaloids, tannins, flavonoids, terpenes, saponins, coumarins, glycosides, phenolics, essentials oils and others which essentially contribute to their biological effects. Phytochemicals have shown an important role in preventing chronic diseases like cancer, diabetes, and coronary heart disease [1]. Therefore, many plant based products have been developed and available not only in the local but also in the international market.

Garcinia mangostana Lin., commonly known as mangosteen, is a fruit-bearing tree that is cultivated in Philippines. It is used to treat fever, skin disease, diarrhea, diabetes, stomach ache and intestinal ailments. It is also reported to contain a variety of secondary metabolites, such as oxygenated and prenylated xanthones [2]. Annona squamosa Lin., commonly called as atis by many Filipinos, was already a part of human diet due to its nutritional and medicinal values. In folkloric medicine, the unripe fruit is used as astringent, and the root is a drastic purgative. Its fruit peel extract contains alkaloids, flavonoids, phenols, saponins, steroids, terpenoids, coumarin [3], and acetogenins [4]. Annona muricata Lin., on the other hand, is commonly known as guyabano in the Philippines. The fruit is used to treat dysentery, mouth sores, fever, and diabetes. It contains alkaloids, flavonoids, carbohydrates, glycosides, saponin, terpenoids, and protein [5]. With the important compositions and significant biological activities of the three medicinal plants, their toxic and teratogenic effects, if any, have not yet been studied, hence, this study.

Zebrafish (Danio rerio), a member of Cyprinidae family, is being used in toxicological and teratological studies primarily due to their various advantages such as transparency of embryo, high fecundity, easy to handle, and inexpensive to raise. Teratogens are substances that may cause defects in normal embryonic development but not necessarily being toxic in adults [6]. Some teratogens such as thalidomide [7] and arsenic [8] are presently used as anticancer drug. 
Herein, we investigated the phytochemical compositions and the toxic and teratogenic effects of the hot water extracts of fruit rinds of select medicinal plants in developing embryos of $D$. rerio.

\section{MATERIALS AND METHODS}

\section{Source of Plant Materials}

The ripe fruits of $A$. squamosa, A. muricata, and G. mangostana were purchased from Science City of Munoz, Nueva Ecija, Philippines. The ripe fruits were washed and peeled off, then the fruit rinds were cut into small pieces and air-dried for 5 days. The dried fruits were pulverized using blender and their powders were subjected to extraction.

\section{Phytochemical Screening}

The bioactive components of each fruit rind were determined based on the chemical test described by Sofowora [9], Trease and Evans [10], and Harborne [11]. Three replicates were prepared in each test. The results were determined based on color and intensity of the action and were noted as present or not detected.

\section{Hot Water Extraction}

The plant materials were separately extracted through hot water extraction protocol. In each fruit rind, $300 \mathrm{ml}$ of distilled water was added to 10 grams of powdered fruit rind in a $1000 \mathrm{ml}$ capacity flask. The mixtures were placed into a double boiler water bath at 80 to $90^{\circ} \mathrm{C}$ for 2 hours. Extracts were filtered using a Whatman filter paper No. 2 and the filtrates were diluted to embryo water [12] to prepare $10 \mathrm{ml}$ of the different concentrations $(3 \%, 2 \%, 1 \%, 0.5 \%, 0.1 \%$, and $0 \%$, control) which served as treatments.

Maintenance and Acclimatization of

\section{Zebrafish}

An aquarium comprising of untreated and clean water with continuous aeration at $26 \pm 1{ }^{\circ} \mathrm{C}$ was maintained for female and male adult zebrafish at a ratiol:2, respectively. Fish were then acclimatized for one week before spawning and fertilization. They were nourished daily with a high protein diet flakes. The high quality of water was maintained.

\section{Zebrafish Spawning and Fertilization}

Zebrafish were confined in a plastic mesh to prevent cannibalism. After which, the zebrafish were subjected in dark condition by wrapping the aquarium with black plastic bag to allow spawning. After 12 hours in the dark condition, the aquarium was exposed to light condition for another 12 hours. Fertilization occurs $30 \mathrm{~min}$ after the light was turned on. Twelve hour post fertilized embryos were siphoned out from the aquarium using a hose and transferred in a beaker. Embryos were rinsed three times with distilled water and 
placed in a Petri plate to check the uniformity and normal conditions of embryos using a compound microscope. Unfertilized or coagulated eggs were not considered.

\section{Teratogenicity and Toxicity Assay}

Two $\mathrm{ml}$ of each treatment concentration of the extract was dispensed into each well of the 12-well ELISA plate. Triplicate was prepared each treatment concentration. Four embryos at segmentation phase were transferred into each well containing the different treatments. The plate was incubated at $26^{\circ} \mathrm{C} \pm 1^{\circ} \mathrm{C}$. Mortality, heartbeat, and hatchability rates were recorded. Teratogenic activity was examined under 40X magnification using a compound microscope. Morphological endpoint evaluation of treated zebrafish was based on the parameters established by Schulte and Nagel [13] and Nagel [14]: lethal (coagulation, tail not detached, no somites, and no heartbeat), teratogenic (malformation of head and tail, scoliosis, growth retardation, stunted tail, and limited movement), and normal. Percentage delayed growth and malformation were determined.

\section{Statistical Analysis}

Experiment was laid out in a Completely Randomized Design (CRD). Data were analyzed using analysis of variance (ANOVA). Duncan's Multiple Range Test
(DMRT) was carried out to compare the treatment effects at 5\% level of significance.

\section{RESULTS AND DISCUSSION}

\section{Phytochemical Constituents of Fruit Rinds}

A number of phytochemicals are present in plants. In this study, five phytochemicals were screened using qualitative analysis in the three samples and the results are presented in Table 1. Apparently, all phytochemicals screened were present in $A$. squamosa, and A. muricata. However, flavonoid was not detected in $G$. mangostana. These phytochemicals are responsible to several biological activities. These qualitative results of $A$. muricata, $A$. squamosa and $G$. mangostana extracts were correspond to findings from previous reported studies. Ethanol extract of pericarp of A. muricata showed the presence of saponins, terpenoid, tannins, flavonoids, and cardiac glycosides [15]. Using petroleum ether, ethyl acetate, and alcohol extraction, $A$. squamosa detected almost all the phytochemicals screened [16]. However, in the study of Kaladhar et al. [3], the pericarp of A. squamosa showed positive result of terpenoid. Moreover, the pericarp of $G$. mangostana also contains some phytochemicals. The chloroform extract of the pericarp showed positive results of terpenoids and flavonoids [17]. However, 
saponins and tannins were not detected in the extract. In the study of Alvarez et al. [18], the methanol extract of the pericarp showed positive result of tannins and cardiac glycoside. However, some phytochemicals including flavonoid was detected in chloroform extracts but not in aqueous extract. These differences are due to the solvent used in the extraction of bioactive components.

Tannins are bioactive compounds that are naturally present in plant. This bioactive compound was detected in the three extracts as indicated by brownish green or blue coloration. This compound is widely distributed in higher plants and members of polyphenol chemical family. This suggests that the presence of tannins in the extracts is tend to be acidic because of the phenolic groups and could possibly be responsible for its antimicrobial activity [19]. Tannins could inhibit the growth of fungi, yeast, bacteria, and viruses [20] and has anti-cancer activity $[21,22]$.

The three extracts showed the presence of saponins through formation of emulsion or stable frothing. This is due to the mixture of the non-polar sapogenin and the watersoluble side chain compound producing visible foam [23]. Saponins have shown biological activities. The isolated saponin, gymnemagenol from Gymnema sylvestre exhibited cytotoxic activity (73\%) on HeLa cells after 96 hours [24]. Saponins also possessed significant antimicrobial and antifungal activities against pathogenic bacteria and fungi [25]. There were some studies exhibiting the activities of saponin in medicinal applications such as anticardiovascular [26], and antiinflammatory activities [27]. They can also interfere the replication of cellular DNA and prevent the proliferation of cancer cells [28].

Another bioactive compound present in plants is flavonoid and its presence in plant extracts can be distinguished by yellow coloration. This coloration was observed in A. muricata and A. squamosa. This naturally occurring compound possesses several biological activities such as antiinflammatory, antimicrobial, anticancer, high antioxidant, and anti-tumor activities $[\mathbf{2 9}, \mathbf{3 0}$, 31, 32, 33].

The terpenoid is also present in the three extracts and is considered as one of many secondary metabolites. This bioactive compound was detected in the three plant extracts by exhibiting a color of reddish brown.Terpenoids exhibited potential use in pharmacological activities such as antiviral, antibacterial, antimalarial, anti-inflammatory, 
inhibition of cholesterol synthesis, and anticancer activities [20].

The last bioactive compound that was screened is the cardiac glycoside and this was detected in all extracts. The brown ring formation indicates the presence of cardiac glycosides. This bioactive compound has been used in therapy for many years in heart failure [34]. Moreover, cardiac glycosides can inhibit cell proliferation and has cytotoxic activity by inducting apoptosis [35]. Therefore, the presence of bioactive compounds in the plants indicates their medicinal values. These findings support the traditional use of the plants in the management of diseases because of their varied pharmacological effects.

\section{Toxic Effects of Fruit Rind Extracts}

This study evaluated the toxic and teratogenic effects of the three fruit rind extracts in zebrafish embryos as animal model. The embryos were exposed in various treatment concentrations and observed at different stages of development from segmentation phase (12 hours), pharyngula stage (24-36 hours), and hatching period (4872 hours). To determine the toxic effects, coagulation and absence of heartbeat were notably observed in treated embryos. Table 2 presents the percentage mortality of embryos after 12, 24, 36, and 48 hours of exposure at different concentrations of $A$. muricata, $A$. squamosa, and G. mangostana fruit rinds hot water extract. The toxic effects of the extracts were found dependent on the time of exposure and concentrations of extracts. The most common toxic effect of the three extracts was coagulation (Figure $1 \mathrm{ACE}$ ). After 12 hours of exposure, $100 \%$ mortality was observed in $2 \%$ and higher concentration of A. muricata and G. mangostana. However, although lower than $100 \%$ mortality, embryos exposed in $2 \%$ of $A$. squamosa showed statistically comparable with $3 \%$. Apparently, the mortality of embryos had increased as the time of exposure prolonged and this evidently observed to embryos at $1 \%$ concentration of all extracts. At 48 hours post treatment exposure, a $100 \%$ mortality was observed in embryos exposed to $0.50 \%$ and higher concentrations of both $A$. muricata and $A$. squamosa and to those at $1.0 \%$ and higher concentrations of $G$. mangostana. In contrast, no mortality was observed to those treated $0.10 \%$ of all extracts.

It is clearly seen that all extracts at $0.5 \%$ and higher concentrations significantly affect the survival of $D$. rerio embryos. Coagulation was the most observed lethal effects on embryos of the three plant extracts. These toxic effects of plant extracts can be attributed to their bioactive component 
detected in phytochemical screening. These compounds have major impact on the embryos causing death as early as 12 hours and prolonged time of exposure to the extracts. For instance, Wahyuni [36] reported that the compound saponins can disturb the development of Aedes egypti by causing retardation of development and weight reduction. Increasing of mortality level of the larvae was also attributed by this compound that can cause hemolysis in the blood vessels causing death of the larvae. Joy and Remani [37] isolated new compound from pericarp of A. squamosa as (-)-ent-kaur-16-en-19-oic acid and 16a,17-dihydroxy-ent-kauran-19-oic acid showed cytotoxicity against different cell lines (He La cervical cancer cell, DLA cells). However, the root of A. muricata demonstrated high cytotoxic effect against HL-60 cells by disrupting the mitochondrial membrane to arrest the G0/G1 phase and inhibit cell proliferation at different concentrations after 24 hours of treatment [38]. Similarly, this activity of A. muricata was also observed in embryos of $D$. rerio by demonstrating growth retardation as the time of exposure prolonged. Acetogenins is another compound abundant among Annonaceae family. This has been reported to possess anticancer properties. The acetogenin, squamostolide isolated from seed of A. squamosa exhibited cytotoxic effect against in vitro bel-7402 and $\mathrm{CNE}_{2}$ human tumor cell lines [39]. The panaxanthone isolated from the pericarp of G. mangostana suppressed the tumor volumes treated with panaxanthone and also significantly lower the metastasis of a mouse model [40]. Moreover, the xanthone of G. mangostana which reported previously to have antiproliferating effect on cancer cells was evaluated its toxic effects in $D$. rerio. The embryos were dead at $250 \mu \mathrm{g} / \mathrm{mL}$ and 125 $\mu \mathrm{g} / \mathrm{mL}$ after 48 hours of incubation. Thus embryos at $62.5 \mu \mathrm{g} / \mathrm{mL}$ and higher concentrations were considered toxic and lethal to embryo. However, no malformation was observed to all the embryos survived [41]. Some plants such as Artocarpus heterophyllus and Tinospora cordifolia also demonstrated toxic effects in $D$. rerio embryos [42, 43].

\section{Heartbeat Rate of Zebrafish}

Heartbeat is an important parameter to determine the viability of developing $D$. rerio embryos. The normal heartbeat rate of $D$. rerio embryos ranges from 120-180 per minute [44]. The heartbeat rates of all embryos at pharyngula stage were monitored and the results are presented in Table 3. Apparently, no heartbeat rate was observed to embryos in $1 \%$ and higher concentrations 
of extracts of A. muricata and G. mangostana and $0.5 \%$ and higher concentrations of $A$. squamosa extract due to coagulation at early stage of embryonic development. The zero values of heartbeat rate means no visual heart beat during the observation period which indicate delayed growth.However, only embryos at $0.1 \%$ of extracts of $A$. muricata and A. squamosa showed obvious heartbeat but lower than those in control. These results suggest that the three plant extracts are cardiotoxic to $D$. rerio embryos. This effect could be attributed to cardiac glycoside present in the three plant extracts. According to Poindexter et al. [45] as cited by Jose et al. [46], the cardiac glycoside was found to inhibit the myocardial Na-K ATPase enzyme that causes an increase in contraction force of the heart which can lead to cardiac arrest.

\section{Hatchability of Zebrafish}

An indicative of successful developmental process is hatching. The mean percentage hatchability of the embryos exposed to various concentrations of $A$. muricata, $A$. squamosa, and G. mangostana extracts is also presented in Table 3.Control embryos completed their hatching period at 48 hours post treatment exposure. The $0.1 \%$ of $A$. muricata extract-treated embryos demonstrated mean percentage hatchability of $33.33 \%$ which was significantly lower than that of the control embryos. No hatched was recorded in those exposed to all concentrations of extracts of A. squamosa and G. mangostana. This is due to early coagulation and obvious delayed growth of embryos. Delayed of hatching process could be attributed possibly to the inhibition of the release of chorionase, an enzyme responsible for hatching [47] by the plant extracts. Another reason for delay or failure to hatch was due to the abnormalities which resulted to the limited movement of treated embryos, thus unable to break the chorion.

\section{Teratogenic Effects of Fruit Rind Extracts}

Delayed growth is one of the distinct teratogenic effects of the three extracts. The percentage delayed growth of embryos exposed in varying concentrations of the extracts after 48 hours was observed and the results are shown in Table 3. Embryos showed $100 \%$ delayed growth when exposed in $0.5 \%$ and higher concentrations of both $A$. muricata and A. squamosa extracts, and in $0.1 \%$ and higher concentrations of $G$. mangostana extract. The $0.1 \%$ concentrations of the first two extracts registered low percentage delayed growth but found statistically comparable to those in control. Aside from delayed growth, the different morphological abnormalities were also observed, and the most common 
abnormality was tail malformation (Figure 1). Bent-tail tip embryos were observed at $0.1 \%$ of both extracts of $A$. muricata and $A$. squamosa. This abnormality is probably due to the disturbance of embryonic development of $D$. rerio. However, embryos treated with G. mangostana extract did not show any malformations, which probably due to the very obvious delayed growth. These embryos were still in advanced segmentation phase (Figure 1F) during the last observation period. In the previous work of Noordin et al. [41], the survived embryos of zebrafish did not show any malformation when exposed to xanthone from the pericarp of $G$. mangostana.

\begin{tabular}{|l|c|c|c|}
\hline \multicolumn{4}{|c|}{ Table 1: Phytochemical composition of fruit rinds of A. muricata, A. squamosa, and G. mangostana } \\
\hline Phytochemical & A.muricata & A.squamosa & G.mangostana \\
\hline Tannin & Present & Present & Present \\
\hline Saponin & Present & Present & Present \\
\hline Flavonoid & Present & Present & Not detected \\
\hline Terpenoid & Present & Present & Present \\
\hline Cardiac Glycoside & Present & Present & Present \\
\hline
\end{tabular}

\begin{tabular}{|c|c|c|c|c|}
\hline \multirow[t]{2}{*}{ Fruit Rind Extract (\%) } & \multicolumn{4}{|c|}{ Mortality (\%) } \\
\hline & $12 \mathrm{~h}$ & $24 \mathrm{~h}$ & $36 \mathrm{~h}$ & $48 \mathrm{~h}$ \\
\hline \multicolumn{5}{|l|}{ A. muricata } \\
\hline 3.00 & $100.00^{\mathrm{a}}$ & $100.00^{\mathrm{a}}$ & $100.00^{\mathrm{a}}$ & $100.00^{\mathrm{a}}$ \\
\hline 2.00 & $100.00^{\mathrm{a}}$ & $100.00^{\mathrm{a}}$ & $100.00^{\mathrm{a}}$ & $100.00^{\mathrm{a}}$ \\
\hline 1.00 & $75.00^{a}$ & $100.00^{\mathrm{a}}$ & $100.00^{\mathrm{a}}$ & $100.00^{\mathrm{a}}$ \\
\hline 0.50 & $\mathbf{0 . 0 0}^{\mathrm{b}}$ & $8.25^{b}$ & $16.75^{b}$ & $100.00^{\mathrm{a}}$ \\
\hline 0.10 & $0.00^{b}$ & $\mathbf{0 . 0 0}^{\mathrm{b}}$ & $0.00^{b c}$ & $0.00^{b}$ \\
\hline 0.00 & $\mathbf{0 . 0 0}^{\mathrm{b}}$ & $\mathbf{0 . 0 0}^{\mathrm{b}}$ & $0.00^{b c}$ & $\mathbf{0 . 0 0}^{\mathrm{b}}$ \\
\hline \multicolumn{5}{|l|}{ A. squamosa } \\
\hline 3.00 & $100.00^{\mathrm{a}}$ & $100.00^{\mathrm{a}}$ & $100.00^{\mathrm{a}}$ & $100.00^{\mathrm{a}}$ \\
\hline 2.00 & $91.75^{\mathrm{a}}$ & $100.00^{\mathrm{a}}$ & $100.00^{\mathrm{a}}$ & $100.00^{a}$ \\
\hline 1.00 & $58.25^{b}$ & $83.25^{a b}$ & $100.00^{\mathrm{a}}$ & $100.00^{\mathrm{a}}$ \\
\hline 0.50 & $0.00^{\mathrm{c}}$ & $0.00^{\mathrm{c}}$ & $100.00^{\mathrm{a}}$ & $100.00^{\mathrm{a}}$ \\
\hline 0.10 & $0.00^{\mathrm{c}}$ & $0.00^{c}$ & $0.00^{b}$ & $\mathbf{0 . 0 0}^{\mathrm{b}}$ \\
\hline 0.00 & $\mathbf{0 . 0 0}^{\mathrm{c}}$ & $\mathbf{0 . 0 0}^{\mathrm{c}}$ & $0.00^{b}$ & $\mathbf{0 . 0 0}^{\mathrm{b}}$ \\
\hline \multicolumn{5}{|l|}{ G. mangostana } \\
\hline 3.00 & $100.00^{\mathrm{a}}$ & $100.00^{\mathrm{a}}$ & $100.00^{\mathrm{a}}$ & $100.00^{a}$ \\
\hline 2.00 & $100.00^{\mathrm{a}}$ & $100.00^{\mathrm{a}}$ & $100.00^{\mathrm{a}}$ & $100.00^{\mathrm{a}}$ \\
\hline 1.00 & $0.00^{b}$ & $41.75^{b}$ & $100.00^{a}$ & $100.00^{a}$ \\
\hline 0.50 & $\mathbf{0 . 0 0}^{\mathrm{b}}$ & $0.00^{\mathrm{c}}$ & $8.25^{b}$ & $75.00^{\mathrm{ab}}$ \\
\hline 0.10 & $0.00^{b}$ & $0.00^{\mathrm{c}}$ & $0.00^{b}$ & $0.00^{c}$ \\
\hline 0.00 & $0.00^{b}$ & $0.00^{\mathrm{c}}$ & $0.00^{b}$ & $0.00^{\mathrm{c}}$ \\
\hline
\end{tabular}




\begin{tabular}{|c|c|c|c|}
\hline Fruit Rind Extract (\%) & $\begin{array}{c}\text { Heartbeat rate } \\
\text { (per minute) }\end{array}$ & $\begin{array}{c}\text { Hatchability } \\
(\%)\end{array}$ & Delayed growth (\%) \\
\hline \multicolumn{4}{|l|}{ A. muricata } \\
\hline 3.0 & NBH & $0.00^{\mathrm{c}}$ & $100.00^{\mathrm{a}}$ \\
\hline 2.0 & NBH & $0.00^{c}$ & $100.00^{\mathrm{a}}$ \\
\hline 1.0 & NBH & $0.00^{\mathrm{c}}$ & $100.00^{\mathrm{a}}$ \\
\hline 0.5 & $0.00^{b}$ & $0.00^{\mathrm{c}}$ & $100.00^{\mathrm{a}}$ \\
\hline 0.1 & $127.00^{\mathrm{a}}$ & $\mathbf{3 3 . 3 3}^{\mathrm{b}}$ & $8.33^{b}$ \\
\hline 0.0 & $137.67^{\mathrm{a}}$ & $100.00^{\mathrm{a}}$ & $0.00^{b}$ \\
\hline \multicolumn{4}{|l|}{ A. squamosa } \\
\hline 3.0 & NBH & $0.00^{b}$ & $100.00^{\mathrm{a}}$ \\
\hline 2.0 & NBH & $0.00^{b}$ & $100.00^{\mathrm{a}}$ \\
\hline 1.0 & NBH & $0.00^{b}$ & $100.00^{\mathrm{a}}$ \\
\hline 0.5 & NBH & $0.00^{b}$ & $100.00^{\mathrm{a}}$ \\
\hline 0.1 & $106.67^{b}$ & $0.00^{b}$ & $16.67^{b}$ \\
\hline 0.0 & $145.33^{\mathrm{a}}$ & $100.00^{\mathrm{a}}$ & $0.00^{b}$ \\
\hline \multicolumn{4}{|l|}{ G. mangostana } \\
\hline 3.0 & NBH & $0.00^{b}$ & $100.00^{\mathrm{a}}$ \\
\hline 2.0 & NBH & $0.00^{b}$ & $100.00^{\mathrm{a}}$ \\
\hline 1.0 & NBH & $0.00^{b}$ & $100.00^{\mathrm{a}}$ \\
\hline 0.5 & $0.00^{b}$ & $0.00^{b}$ & $100.00^{\mathrm{a}}$ \\
\hline 0.1 & $0.00^{b}$ & $0.00^{b}$ & $100.00^{\mathrm{a}}$ \\
\hline 0.0 & $150.67^{\mathrm{a}}$ & $100.00^{a}$ & $0.00^{b}$ \\
\hline \multicolumn{4}{|c|}{$\begin{array}{l}\text { Values are expressed as mean of three replicates each concentration of extracts. Means with the same letter } \\
\text { of superscript are not significantly different at } \mathrm{P}<0.05 \text { using DMRT. NBH; no heart beat due to coagulation } \\
\text { at early stage of embryonic development. Zero values in heart beat rate column means no visual heart beat } \\
\text { during the observation period which indicate delayed growth. }\end{array}$} \\
\hline
\end{tabular}
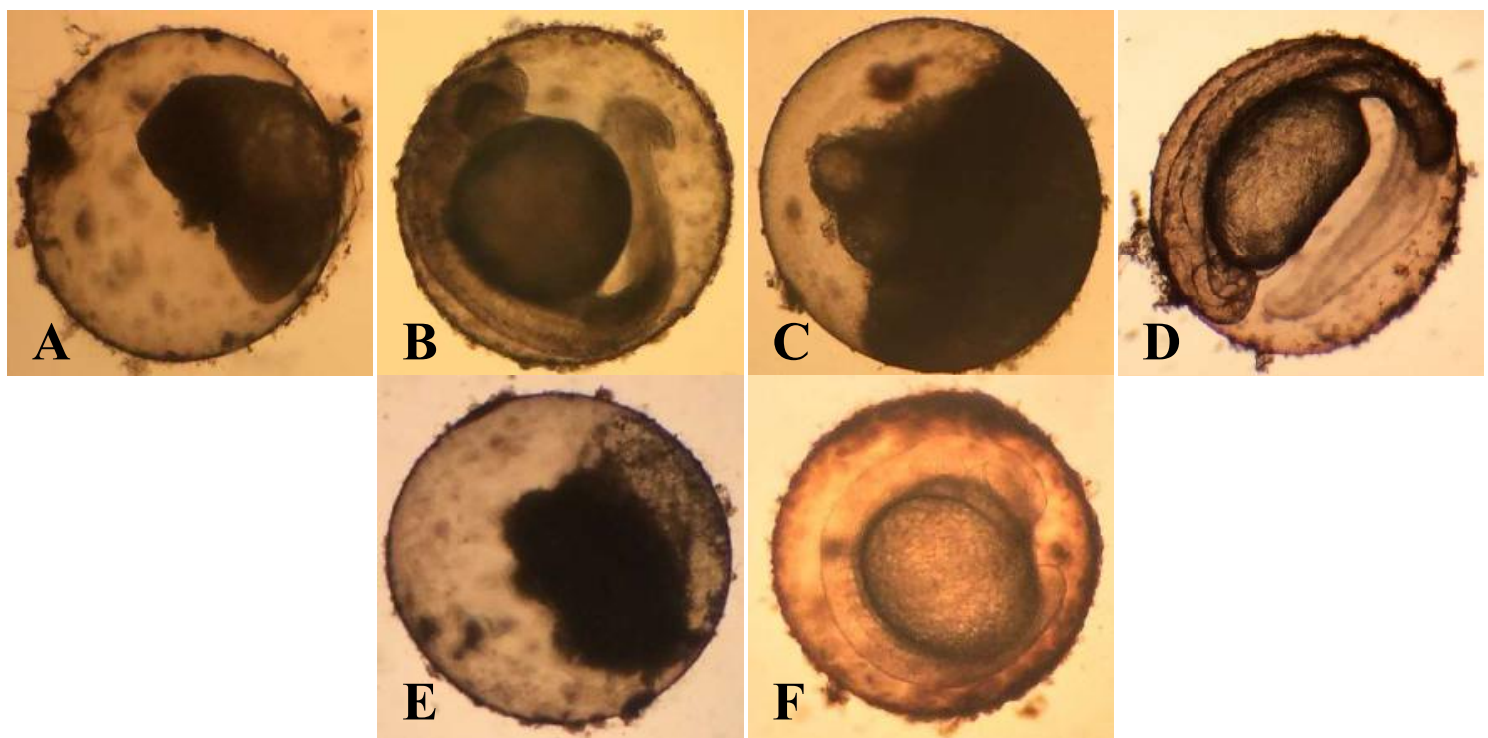

Figure 1.Toxic and teratogenic effects of the three fruit rind extracts: (ACE) coagulated embryos exposed at higher concentrations of the three extracts; (BD) bent-tail tip embryos treated with $0.1 \%$ of $A$. muricata and $A$. squamosa extracts; and (F) delayed growth embryo at $0.1 \%$ of $G$. mangostana extract 


\section{CONCLUSION}

Taken the data together, extracts of the three fruit rinds contained phytochemicals with valuable pharmacological properties and exhibited toxic and teratogenic activities in the embryonic development of zebrafish. Coagulated and delayed growth were the most common toxic and teratogenic effects of the three extracts, respectively.

\section{REFERENCES}

[1] Saxena M, Saxena J, Nema R, Singh D, Gupta A. Phytochemistry of medicinal plants. Journal of Pharmacognosy and Phytochemistry, 2013, Article ID 2668735-5.

[2] Akao Y, Nakagawa Y, Inuma M, Gifu YN. Anti-cancer effects of xanthones from pericarps of mangosteen. International Journal of Molecular Sciences, 2008, 9, 355-370.

[3] Kaladhar DSVGK, Duddukuri GR, Yarla NS. Phytochemical analysis, antioxidant and antimicrobial activities from raw fruit peel crude extracts of Annona squamosa Linn. World Journal of Pharmacy and Pharmaceutical Sciences, 2014, 4(1), 1373-1380.

[4] Jaramillo MC, Arango GJ, Gonzalez MC, Robledo SM, Velez ID. Cytotoxicity and antileishmanial activity of Annona muricata pericarp. Fitoterapia, 2000, 183186.

[5] Solomon-Wisdom GO, Ugoh SC, Mohammed B. Phytochemical screening and antimicrobial activities of Annona muricata (L) leaf extract. American Journal of Biological, Chemical and Pharmaceutical Sciences, 2014, 2(1), 0107.

[6] Mayshar Y, Yanuka O. Teratogen screening using transcriptome profiling of differentiating human embryonic stem cells. Journal of Cellular and Molecular Medicine, 2011, 15(6), 1393-1401.

[7] Teo SK, Stirling DI, Zeldis JB. Thalidomide as a novel therapeutic agent: new uses for an old product. Drug Discovery Today, 2005, 10, 107-114.

[8] Zhu J, Chen Z. How acute promyelocytic leukaemia revived arsenic?. Nature Reviews Cancer, 2002, 2, 705-713.

[9] Sofowara A. Medicinal plants and tradition medicine in Africa. Spectrum books, Ltd., Ibadan, Nigeria, 1993, 289.

[10] Trease GE, Evans WC. Pharmocognosy. $11^{\text {th }}$ edition. Braillier Tiride land Macmillan Publishers. 1989.

[11] Harborne JB. Textbook of phytochemical methods, Champman and Hall Ltd, London. 1973, 110-113. 
[12] Thomas, J., 2000. The Zebrafish Book, 4th edition, University of Oregon. Retrieved on July 2, 2011 fromhttp://www.swarthmore.edu/Na tSci/sgilber1/DB_lab/Fish/fish_solutions. html.

[13] Schulte C, Nagel R. Testing acute toxicity in embryo of zebrafish, Brachydanio rerio as alternative to the acute fish test - preliminary results. ATLA, 1994, 22, 12-19.

[14] Nagel R. DarT: The embryo test with the zebrafish (Danio rerio) - a general model in ecotoxicology and toxicology. ALTEX, 2002, 19, 10-12.

[15] Ojezele OJ, Ojezele MO, Adeosun AM. Comparative phytochemistry and antioxidant activities of water and ethanol extract of Annona muricata Linn leaf, seed, and fruit. Advances in Biological Research, 2016, (4), 230-235.

[16] Sharma A, Sharmab AK, Chanda T, Khardiyaa M, Agarwal S. 2013. Preliminary phytochemical screening of fruit peel extracts of Annona squamosa Linn. Current Pharma Research, 2013, 4(1), 1038-1043.

[17] Sivakumari K, Manimekalai I, Ashok K, Rajesh S. Phytochemical profiling of mangosteen fruit, Garcinia mangostana. World Journal of Pharmacy and
Pharmaceutical Sciences, 2016, 5(2), 221-252.

[18] Alvarez MR, Bueno PR, Cruz RO, Francis RM, Vallesfin J, Heralde F. Phytochemical analysis and salivary amylase inhibition activities of Carica papaya leaf and Garcinia mangostana pericarp extracts and partially purified fractions. International Journal of Pharmaceutical and Phytopharmacological Research, 2016, 6(1), 34-40.

[19] Njoku O, Obi C. Phytochemical constituents of some selected medicinal plants. African Journal of Pure and Applied Chemistry, 2009, 3(11), 228233.

[20] Visweswari G, Christopher R, Rajendra W. Phytochemical screening of active secondary metabolites present in Withania somnifera root: role in traditional medicine. International Journal of Pharmaceutical Sciences and Research, 2013, 4(7), 2770-2776.

[21] Gonzalez-Sarria A, Yuan T, Seeram NP. Cytotoxicity and structure activity relationship studies of maplexins A-I, gallotannins from red maple (Acer rubrum). Food Chemistry Toxicology, 2012, 50,1369-1376. 
[22] Wang CC, Chen LG, Yang LL. Cuphiin D1, the macrocyclic hydrolyzable tannin induced apoptosis in HL-60 cell line. Cancer Letters, 2000, 149, 77-83.

[23] Zulkifli K, Abdullah N, Abdullah A, Aziman N, Kamarudin W. Phytochemical screening and activities of hydrophilic and lipophilic antioxidant of some fruit peels. The Malaysian Journal of Analytical Sciences, 2012, 16(3), 309317.

[24] Khanna VG, Kannabiran K. Anticancercytotoxic activity of saponins isolated from the leaves of Gymnema sylvestre and Eclipta prostrata on HeLa cell. International Journal of Green Pharmacy, 2009, 3(3), 227-229.

[25] Khanna VG, Kannabiran K. Antimicrobial activity of saponin fractions of the leaves of Gymnema sylvestre and Eclipta prostrata. World Journal of Microbiology and Biotechnology, 2008, 24, 27-37.

[26] Moghimipour E, Handali S. Saponin: properties, methods of evaluation and applications. Annual Research \& Review in Biology, 2015, 5(3), 207-220.

[27] Patel PP, Patil PH. Anti-inflammatory activity of saponin rich fraction isolated from the Thespesia populnea (L.) leaves. International Journal of Biomedical and
Pharmaceutical Sciences. 2012, 3(4), 1526-1532.

[28] Yildirim I, Kutlu T. Anticancer agents: saponin and tannin. International Journal of Biological Chemistry, 2015, 9(6), 332340.

[29] Aiyelaagbe OO, Osamudiamen PM. Phytochemical screening for active compounds in Mangifera indica leaf from Ibadan, Oyo State. Plant Sciences Research, 2009, 2(1), 11-13.

[30] Cushnie TP, Lamb AJ. Antimicrobial activity of flavonoids. International Journal of Antimicrobial Agents, 2005, (5), 343-56.

[31] Chahar MK, Sharma N, Dobhal MP, Joshi YC. Flavonoids: A versatile source of anticancer drugs. Pharmacognosy Reviews, 2011, 5(9), 1-12.

[32] Pietta PG. Flavonoids as antioxidant. Journal of Natural Products, 2000, 63, 1035-1042.

[33] Kanadaswami C, Lee T, Lee PH, Hwang JJ, Ke FC, Huang YT, Lee MT. The antitumor activities of flavonoids. In vivo, 2005, (19), 895-910.

[34] Babula P, Masarik M, Adam V, Provaznik PI, Kize R. From $\mathrm{Na}+/ \mathrm{K}+-$ ATPase and cardiac glycosides to cytotoxicity and cancer treatment. Anti- 
Cancer Agents in Medicinal Chemistry, 2013, 13(7), 1069-1087.

[35] Rosenkranz V, Wink M. Induction of apoptosis by alkaloids, non-protein amino acids, and cardiac glycosides in human promyelotic HL-60 cells. Zeitschrift fur Naturforschung C, 2007, 62, 1-6.

[36] Wahyuni D. New bioinsecticide granules toxin from extract of papaya (Carica papaya) seed and leaf modified against Aedes aegypti larvae. Procedia Environmental Sciences, 2015, 23, 323328.

[37] Joy B, Remani P. Antitumor constituents from Annona squamosa fruit pericarp. Medical Chemistry Research, 2008, 17, 345-355.

[38] Pieme CA, Kumar SG, Dongmo MS, Moukette BM, Boyoum FF, Ngogang JY, Saxena AK. Antiproliferative activity and induction of apoptosis by Annonna muricata (Annonaceae) extract on human cancer cells. Complementary and Alternative Medicine, 2014, 14, 516-525.

[39] Xie HH, Wei XY, Wang JD, Liu MF, Yang RZ. A new cytotoxic acetogenin from the seeds of Annona squamosa. Chinese Chemical Letters, 2003, 14(6), 588-590.

[40] Shibata MA, Matoba Y, Tosa H, Iinuma M. Effects of mangosteen pericarp extracts against mammary cancer. Alternative and Integrative Medicine, 2013, 2(8), 1-5.

[41] Noordin MAM, Noor MM, Kamaruddin WMAW, Lazim AZ, Fazry S. Toxicity test of xanthone from mangosteen on zebrafish embryos. 2016, Article ID 020014-1.

[42] Romagosa CMR, David ES, Dulay RMR. Embryo-toxic and teratogenic effects of Tinospora cordifolia leaves and bark extracts in zebrafish (Daniorerio) embryos. Asian Journal of Plant Science and Research, 2016, 6(2), 37-41.

[43] Meman MAC, Dulay RMR, David ES. Teratogenic effects of lyophilized water extracts of leaves and stem-bark of Artocarpus heterophyllus in zebrafish (Danio rerio) Embryo. International Journal of Biology, Pharmacy and Allied Sciences, 2016, 5(6), 1351-1360.

[44] Mably JD, Childs SD. Developmental physiology of the zebrafish cardiovascular system. Fish Physiology, 2010, 10, 1546-5098.

[45] Poindexter BW, Feng A, Dasgupta A, Bick R. Oleandrin produces changes in intracellular calcium levels in isolated cardiomyocytes, a real-time fluorescence imaging study comparing adult to neonatal cardiomyocytes. Journal of 
Toxicology and Environmental Health A, 2007, 70, 568-574.

[46] Jose BV, Dulay RMR, David ES. Toxic

and teratogenic assessment of mangosteen (Garcinia mangostana L.) leaves and stem-bark lyophilized water extracts in zebrafish (Danio rerio) embryo. Advances in Environmental Biology, 2016, 10(5), 96-101.

[47] Sreedevi B, Suvarchala G, Philip GH. Morphological and physiological abnormalities during development in zebrafish due to chlorpyrifos. Indian Journal of Science Research, 2014, 5(2), $1-8$. 